\title{
Trends in Diarrhoeal Diseases, City of Bulawayo Clinics, 2007-2012
}

\author{
Cynthia Ncube ${ }^{1 *}$, Chiedza Sibanda ${ }^{2}$ \\ ${ }^{1}$ Department of Community Medicine, University of Zimbabwe, Zimbabwe \\ ${ }^{2}$ City Health Department, Bulawayo City Council, Zimbabwe
}

\begin{abstract}
Diarrhoeal diseases are a public health concern and constitute about 5\% of all main causes of outpatient department visits in the city of Bulawayo. We conducted a dataset analysis of diarrhoeal diseases to determine how the trends have varied over the years. A descriptive cross-sectional study based on an electronic database for diarrhoeal diseases (2007-2012) was conducted. Data was collected using compilation forms and checklists, then analysed using Microsoft Excel. Three key informants were interviewed. The formula, (Mean $+1.5 S D)$, was used to calculate thresholds for bloody diarrhoea. There were more watery than bloody diarrhoeal cases throughout the review period, with 2008 having the highest number of such cases under 5. In Northern Suburbs, there was a general decrease in both types of diarrhoea cases in both age groups $(<5$ and $>5)$ whilst in Emakhandeni; there was an increase in bloody diarrhoea incidence after 2009. The incidence rate for bloody diarrhoea was higher for females throughout. There was an increase in the number of stool specimens collected for examination between 2008 and 2012. Overall, there was a decrease in the incidence of diarrhoea in Bulawayo city, partly due to regular anti-diarrhoeal campaigns. Following the study, the following measures were implemented: Health education to improve hygienic practices; advocacy for improved water and sanitation in Cowdray Park; rotavirus vaccination for under-fives; maintenance of all records on diarrhoea and up to date thresholds in all clinics for use in monitoring diarrhoea.
\end{abstract}

Keywords: City of Bulawayo, Diarrhoeal Trends, Zimbabwe.

\section{Introduction}

Diarrhoea is the passage of three or more loose or liquid stools per day or more frequent passage than is normal for the individual. Frequent passing of formed stools is not diarrhoea, nor is the passing of loose, "pasty" stools by breastfed babies [1,2]. Although most episodes of childhood diarrhoea are mild, acute cases can lead to significant fluid loss and dehydration, which might result in death or other severe consequences if fluids are not replaced at the first sign of diarrhoea [3]. Diarrhoea is a common symptom of gastrointestinal infections caused by a wide range of pathogens, including bacteria, viruses, and protozoa. The major bacterial pathogens include E Coli, Shigella, Campylobacter, and Salmonella, as well as
Vibrio cholerae during epidemics [3]. The infectious organisms causing diarrhoea are transmitted from one individual to another via the faeco-oral route [4]. There are three clinical types of diarrhoea; acute watery diarrhoea, acute bloody diarrhoea, and persistent diarrhoea.

Diarrhoeal disease is a leading cause of child morbidity and mortality in the world and mostly results from contaminated food and water sources. In children under five years of age, diarrhoeal disease is the second leading cause of death - second only to pneumonia [1]. In 2004 the World Health Organisation pegged the burden of disease for diarrhoea in Zimbabwe at 6700 deaths per year [5]. In 2010, about $8 \%$ of all causes of deaths in children under the age of five years were due to diarrhoea [6]. 
In the City of Bulawayo, diarrhoeal diseases are one of the major causes of Out-Patients Department (OPD) attendances and constitute about $5 \%$ of all main causes of OPD visits. They occur mostly among children below five years [7]. Information about diarrhoeal cases is collected weekly and compiled by the Health Information Office. The dataset was originally intended for the detection of outbreaks and planning purposes. The key variables captured by the dataset are a type of diarrhoea (bloody or watery), the age of the patient, and the reporting clinic. Surveillance for diarrhoea is essential to monitor the disease and be able to detect outbreaks [8].

Diarrhoeal diseases are of public health concern in the city of Bulawayo, especially in the Emakhandeni division. The incidence rate for the first quarter of 2012 for Northern Suburbs was 2.8 per 1000 population, for Nkulumane 4 per 1000 population, for Emakhandeni 4.9 per 1000 population, and for Bulawayo City 4 per 1000 population. We, therefore, conducted a dataset analysis of diarrhoeal diseases to determine how the trends have varied over the years. The study sought to describe diarrhoeal trends by time, place, and person; describe diarrhoeal diseases by type of diarrhoea; determine the trends in the proportion of stool samples collected for laboratory examination during the review period and to determine threshold levels for bloody diarrhoea. The findings of the study helped to plan interventions to prevent and control diarrhoea.

\section{Methods}

A descriptive cross-sectional study based on secondary data was conducted. The Electronic Database for diarrhoeal diseases at the Health Information Office, City of Bulawayo for the period 2007-2012 was used. All cases of diarrhoea regardless of the type seen at City of Bulawayo Clinics for the period January 2007 to December 2012 were included in the study. The study unit was a case of diarrhoea captured in the City of Bulawayo Clinics from January 2007 to December 2012.

Convenience sampling of all diarrhoeal cases captured in the City of Bulawayo Clinics from January 2007 to December 2012 was done.

Compilation forms and checklists were used to collect data. All the data was retrieved from the diarrhoeal diseases electronic database at the Health Information Unit, City of Bulawayo. Analysis of completed compilation forms from the health information department was done. Data were entered into Microsoft Excel 2007 and analyzed to generate graphs. The Senior Health Promotion Officer, Divisional Environmental Health Officer, and Environmental Health Officer were interviewed to seek clarification of observed trends.

Bloody diarrhoea data for five years (20082012), was retrieved from the database. The formula (mean + 1.5SD), was used to calculate thresholds for bloody diarrhoea. Using Microsoft Excel, the bloody diarrhoea cases were listed from week 1 to week 52 for each year, excluding outbreak years (2008 and 2009). After that, the formula (mean $+1.5 \mathrm{SD}$ ) was entered into Excel and used to generate figures for week 1 to week 52. After that, the third quartile Q3, was calculated for each week and a graph was generated. The (mean + 1.5SD) line became the action threshold, and Q3 line was the alert threshold.

Permission to proceed was obtained from the Director of Health Services and the Health Studies Office. All collected data was kept confidential and anonymous with no indication of case names. Informed, signed written consent was sought from all key informants before interviews were done.

\section{Results}

Figure 1 shows the incidence of watery and bloody diarrhoea in the city of Bulawayo. 


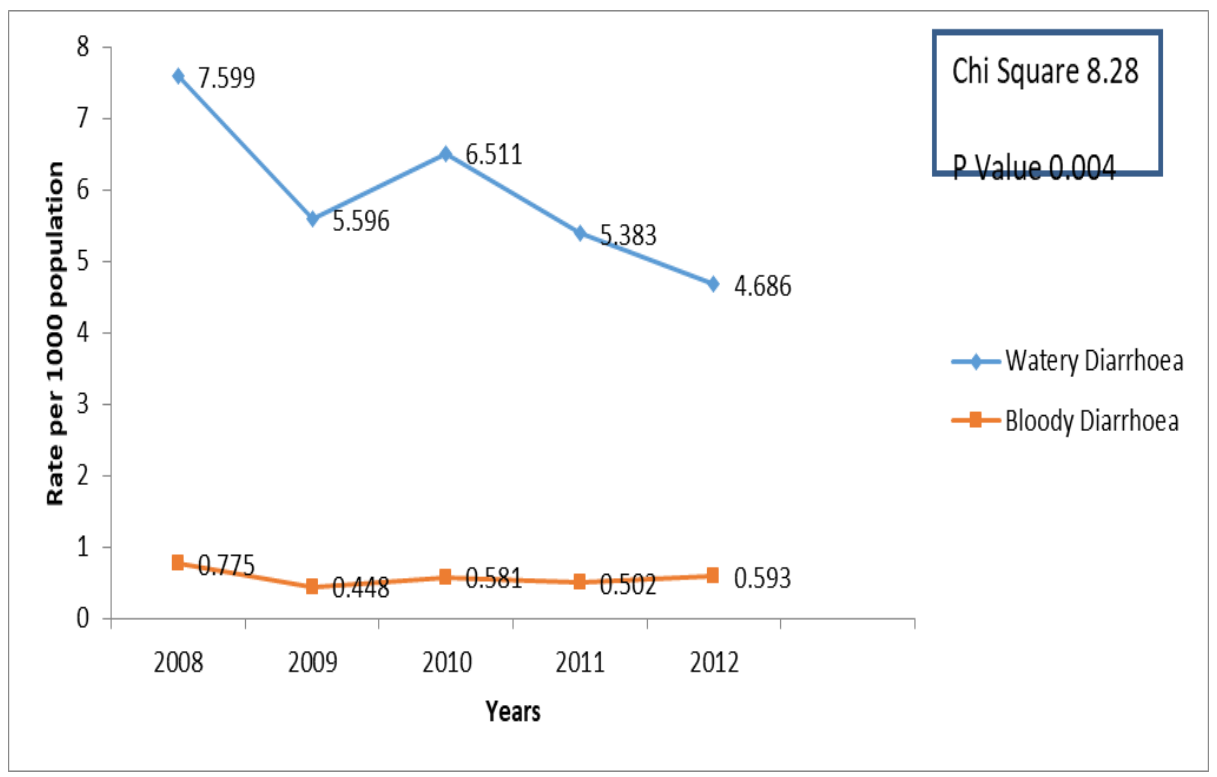

Figure 1. Trends in Diarrhoeal Diseases, City of Bulawayo, 2008-2012

Watery diarrhoea diseases were more than bloody diarrhoea diseases for all the years under review. While the highest incidence rate of $8 \%$ for watery diarrhoea was experienced in 2008, $1 \%$ of bloody diarrhoea was experienced in the same year. Although watery diarrhoea was lower in children under five years of age in 2008, this changed in 2009. Watery diarrhoea in this age group increased up to 2010 and then stared decreasing again. In comparison, watery diarrhoea for those aged five years and above was highest in 2008 but showed a gradual decrease up to 2011. This is shown in Figure 2.

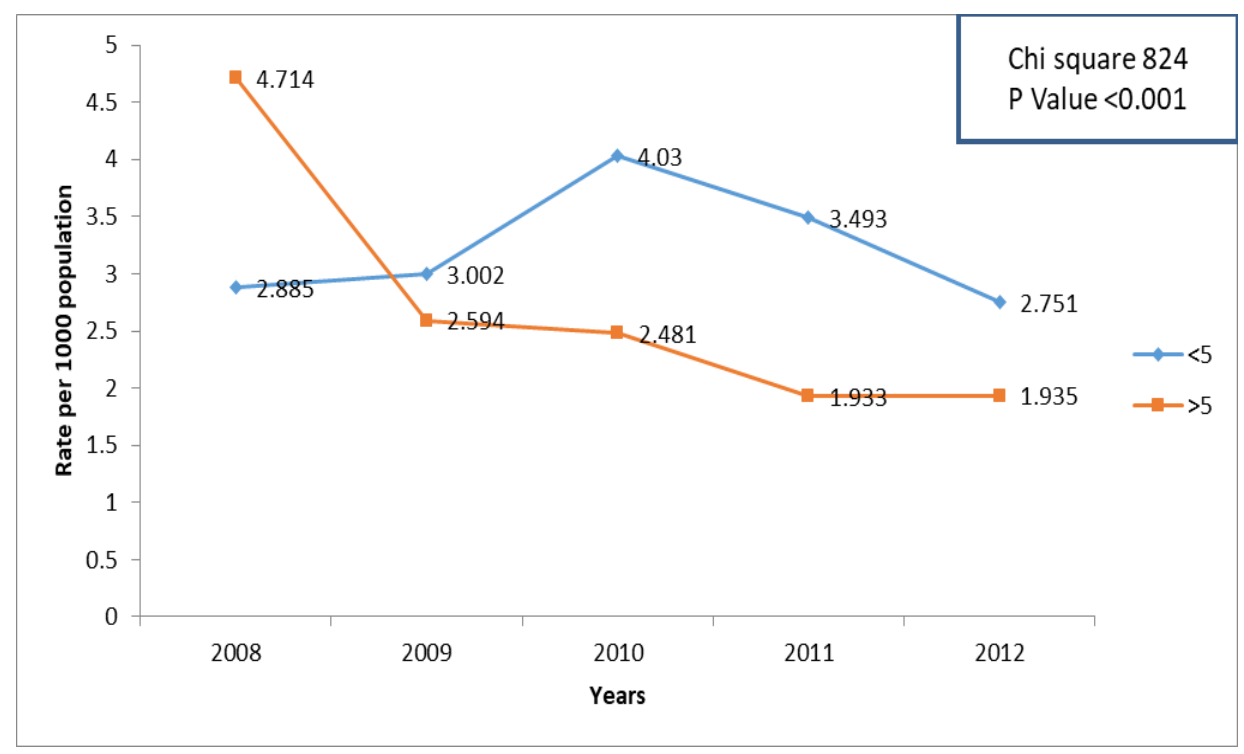

Figure 2. Trends in Watery Diarrhoea by Age, City of Bulawayo, 2007-2012

There was a general increase in bloody diarrhoea in children under five during the review period. In those aged 5 years and above, there was a sharp drop in bloody diarrhoeal cases in 2008 , followed by a slight general increase up to 2012 - Figure 3. 


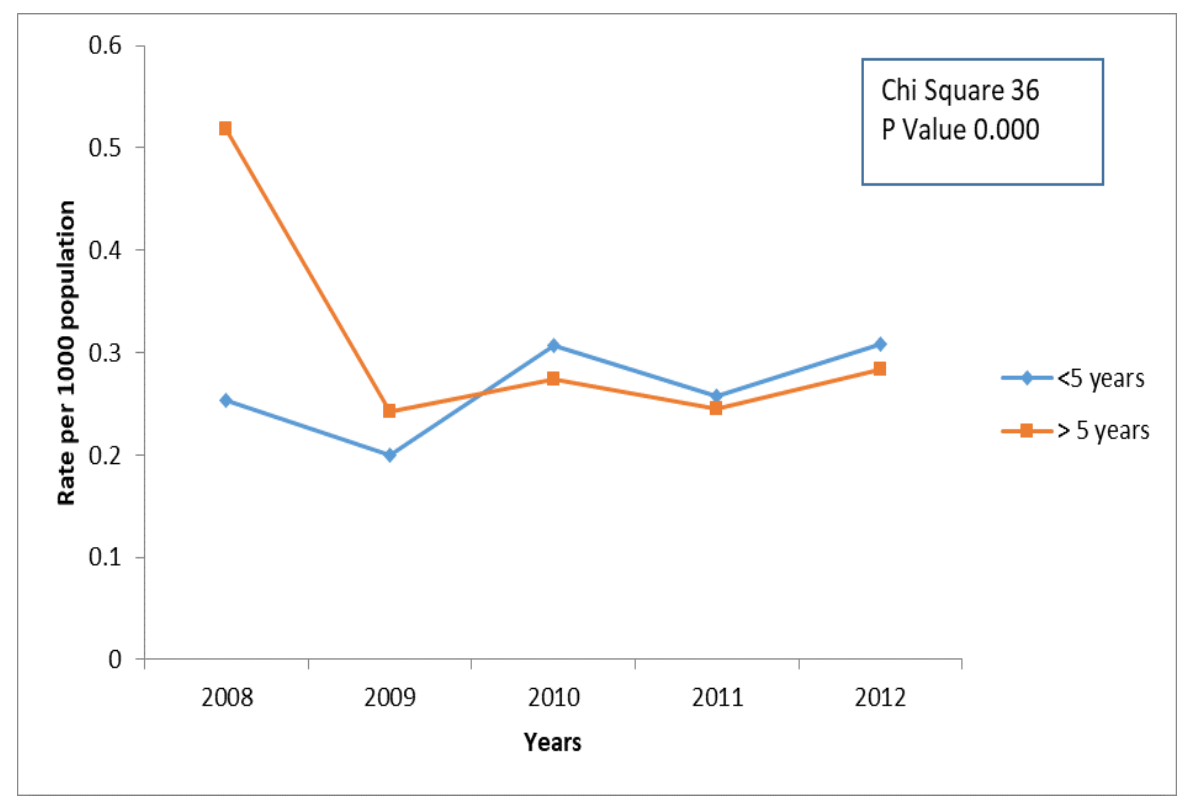

Figure 3. Trends in Bloody Diarrhoea by Age, City of Bulawayo, 2008-2012

There was a general increase in the number of bloody diarrhoea cases for both sexes from 2007 to 2010 . After that, there was a slight increase in both sexes - Figure 4.

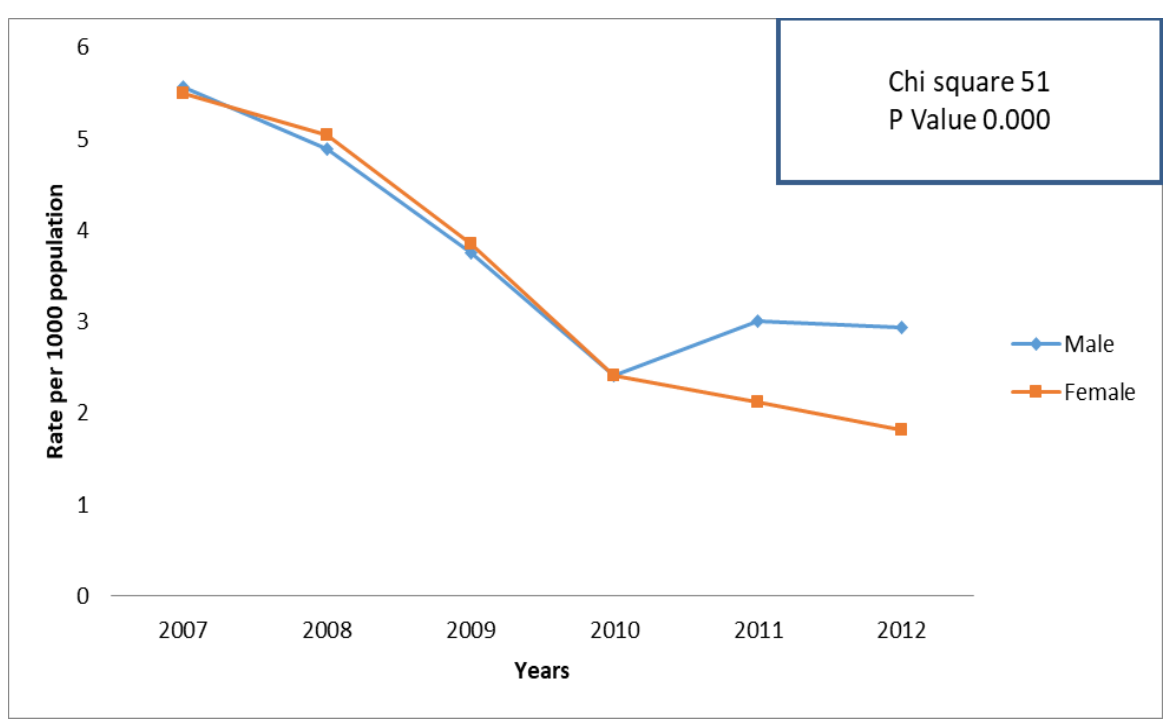

Figure 4. Trends in Watery Diarrhoea by Gender, City of Bulawayo, 2007-2012

In Northern Suburbs, there was a sharp decline in the number of males and females with watery diarrhoea between 2007 and 2010. An increase was noted between 2010 and 2011, followed by a decrease between 2011 and 2012 . The number of males and females with watery diarrhoea was similar throughout the review period. There was a general decrease in watery diarrhoea cases in both age groups during the review period. However, from 2007 to 2009, there were more cases aged 5 years and above compared to children under the age of five: A sharp decline in bloody diarrhoea cases was noted in the division between 2007 and 2009 . After 2009, a slight increase in the number of cases was noted. There was a general decrease in bloody diarrhoea for both age groups during the review period. However, a notable sharp increase in those aged five years and above between 2007 and 2008 is worth mentioning.

In Emakhandeni Division, there was a general decrease in the number of watery diarrhoeal 
cases in both sexes during the review period. The number of males and females with watery diarrhoea was similar. There was a decrease in bloody diarrhoea incidence in the division between 2007 and 2009. After that, a slight increase was noted, in both males and females. The number of males and females with bloody diarrhoea was similar. There was a sharp increase in watery diarrhoea for both age groups between 2007 and 2009. After that, a sustained decrease was noted in children less than five years, whilst an increase was noted in those aged five years and above between 2010 and 2011. There was a sharp decrease in bloody diarrhoea in both age groups between 2007 and 2009. After 2010, there was an increase in bloody diarrhoea in both age groups, although the rate of increase was higher in children less than 5 years compared to those aged 5 years and above.

In Nkulumane, a sharp decrease in watery diarrhoea was noted between 2007 and 2010 . After 2010, a decrease followed by a slight increase was noted in males. On the other hand, an increase followed by a decrease was noted in females. The number of males and females with watery diarrhoea was similar. There was a gradual decrease in bloody diarrhoea from 2007 to 2010. Between 2010 and 2012, a sharp increase was noted in both males and females. However, the incidence rate was higher for females throughout the period under review. Between 2007 and 2008, there was a slight increase in watery diarrhoea in those aged 5 years and above compared to a slight decrease in children less than five during the same period. Between 2008 and 2010, a very sharp decrease in watery diarrhoea was noted in those aged 5 years and above, compared to a slight increase in children less than 5 between 2008 and 2009, followed by a sharp decrease between 2009 and 2010. Bloody diarrhoeal trends by age were also assessed in Nkulumane Division. A gradual decrease in bloody diarhoea was noted between 2007 and 2010 in children less than five years of age. For those aged 5 years and above, there was a sharp decline in bloody diarrhoea between 2007 and 2009. Between 2010 and 2012, a sharp increase in bloody diarrhoea was noted in both age groups, as shown by Figure 5.

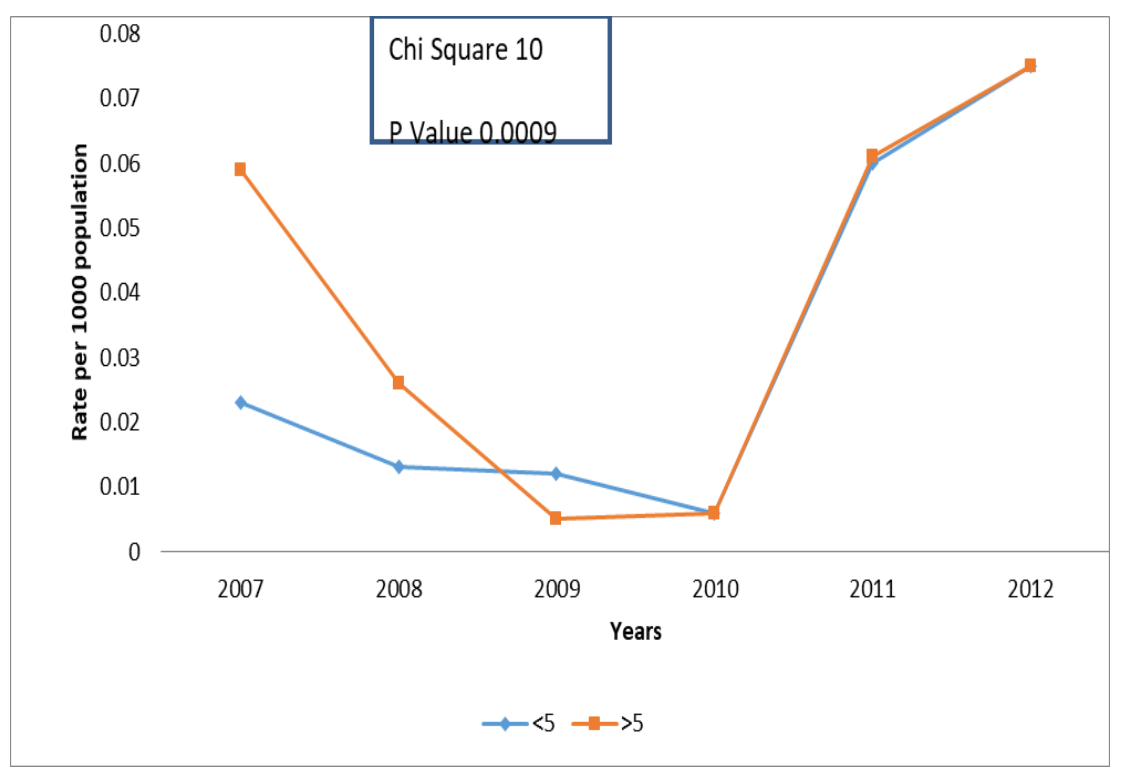

Figure 5. Trends in Bloody Diarrhoea by Age, Nkulumane, 2007-2012

Trends in watery and bloody diarrhoea for all divisions, as well as the total for the whole city, were also compared as shown by Figures 6 and 7. 


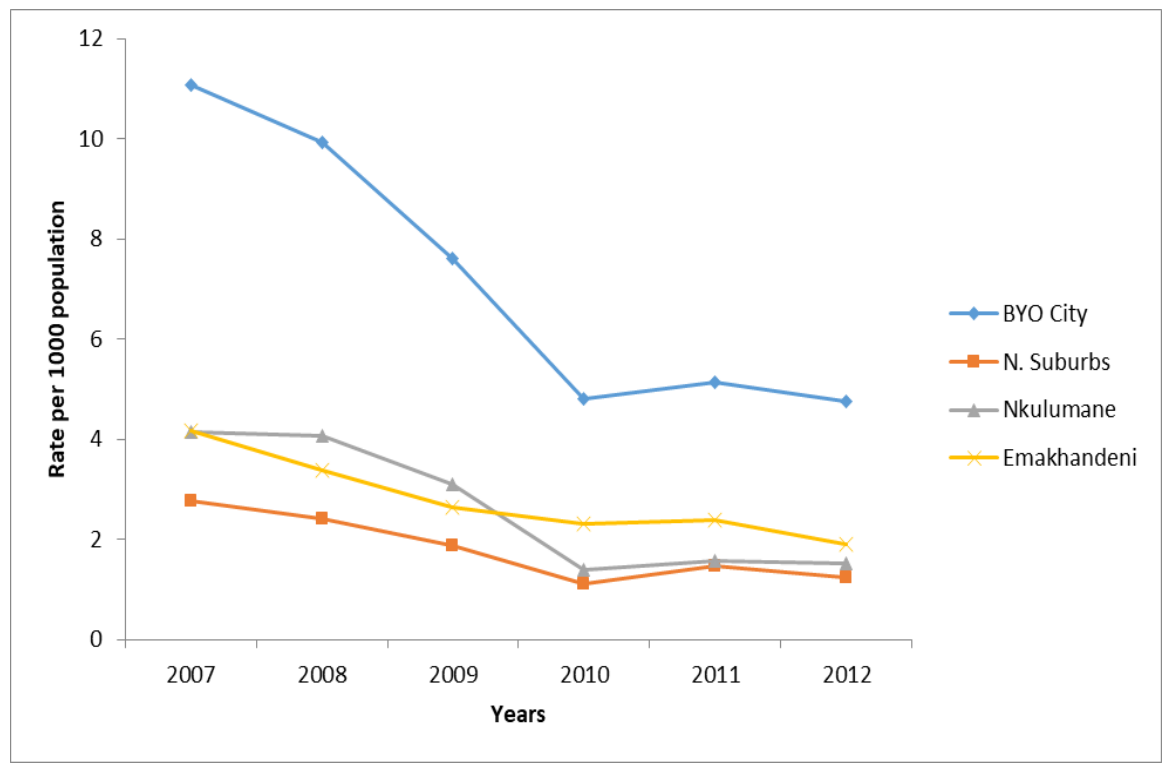

Figure 6. Trends in Watery Diarrhoea by Division, City of Bulawayo, 2007-2013

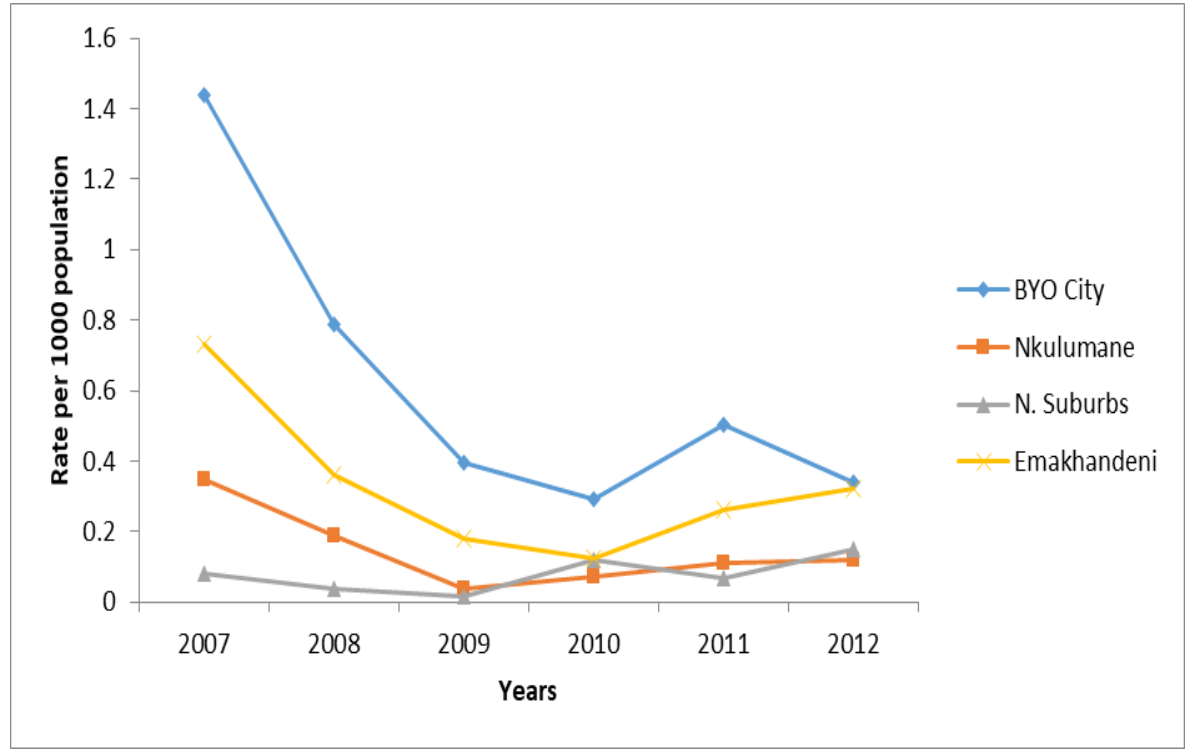

Figure 7. Trends in Bloody Diarrhoea by Division, City of Bulawayo, 2007-2013

Overall, Northern Suburbs Division had the lowest incidence of watery diarrhoea throughout the whole review period, whilst Nkulumane had the highest between 2007 and 2009. After 2009, Emakhandeni had the highest incidence up to 2012. Northern Suburbs had the lowest incidence of bloody diarrhoea, whilst Emakhandeni had the highest throughout the review period.
Concerning collection of stool specimens for examination at the Mpilo microbiology laboratory, there was an increase in the number of diarrhoeal stools specimens collected between 2008 and 2012. Threshold levels for bloody diarrhoea for all the clinics in the city were also calculated. This is shown in Figures 8 and 9 respectively. 


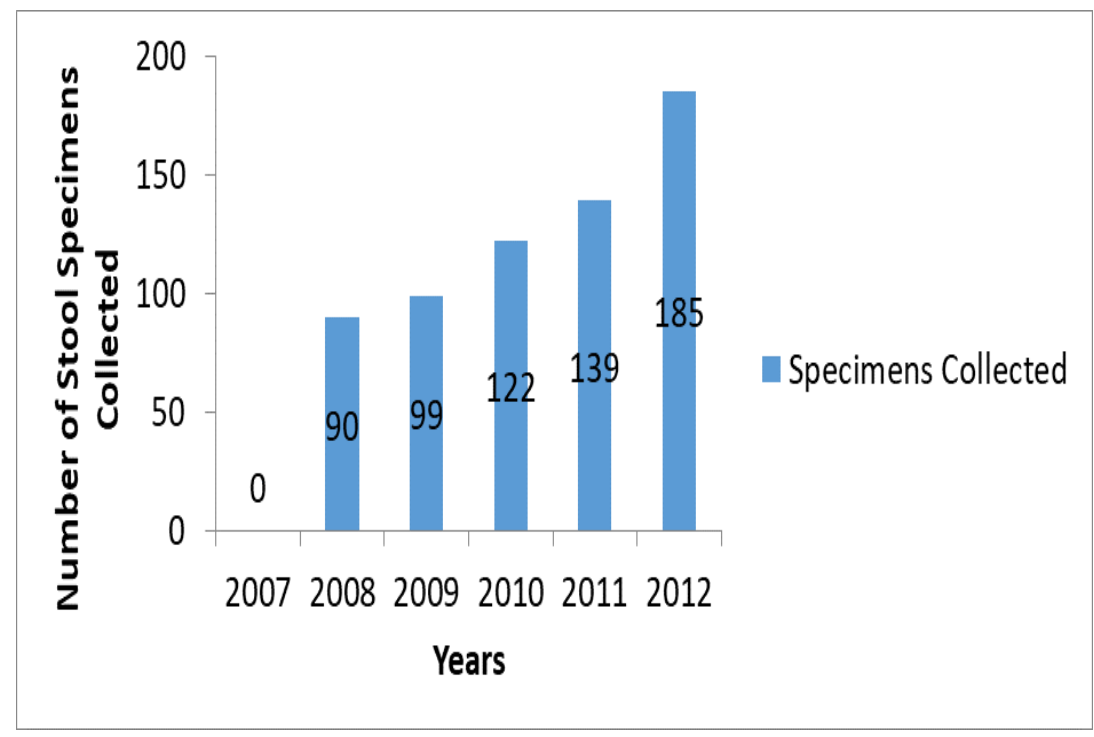

Figure 8. Proportion of Stool Samples Collected for Laboratory Investigation, City of Bulawayo, 2007-2012 *Information for 2007 was missing in some indicates missing data. clinics, and hence 2007 was excluded. The zero

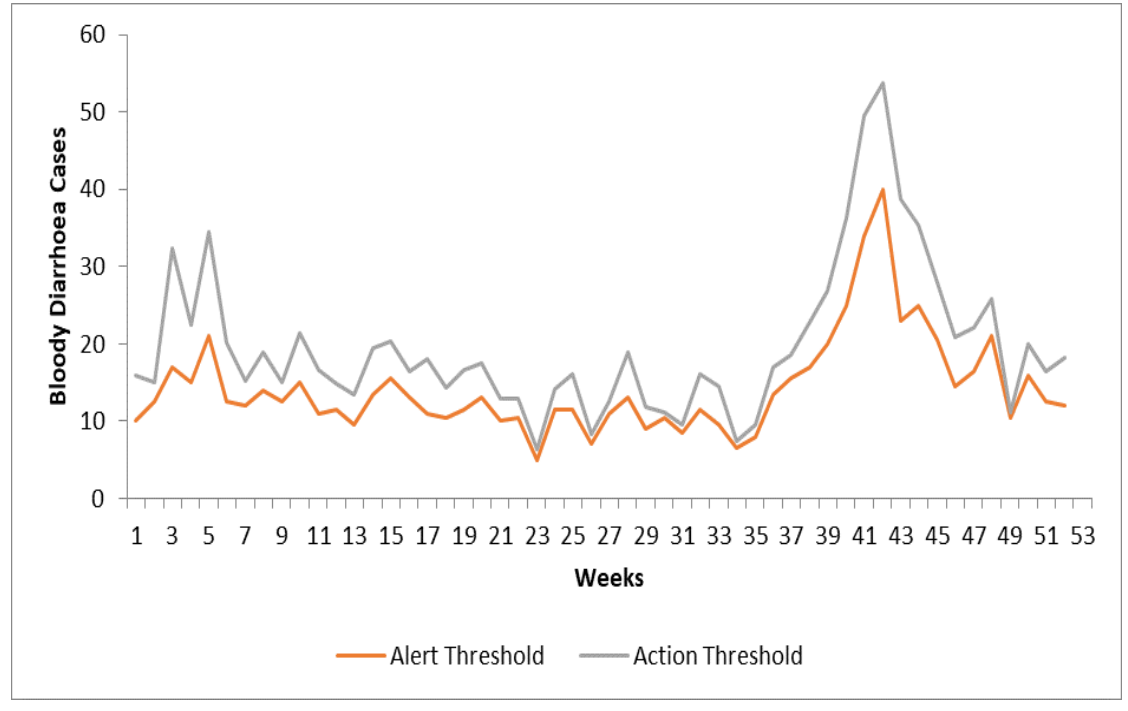

Figure 9. Threshold Levels for Bloody Diarrhoea, City of Bulawayo, 2013

\section{Discussion}

In Bulawayo City, there were more watery diarrhoea cases than bloody diarrhoea cases throughout the review period. This is because out of the three known types of diarrhoea; watery diarrhoea, acute bloody diarrhoea, and persistent diarrhoea; watery diarrhoea is the most common, especially in children less than five years [4]. In addition, being HIV (Human Immune Virus) positive is a risk factor for persistent watery diarrhoea. In Bulawayo, the HIV prevalence is $19 \%$, the second-highest in the country after
Matabeleland South. HIV infection may be contributing to the higher incidence of watery diarrhoea in the city [9].

The highest incidence of both watery and bloody diarrhoea in the city occurred in the year 2008. During the period November 2008 to March 2009, Bulawayo city, like all other provinces in the country, experienced a cholera outbreak. The cholera outbreak was preceded by a sudden increase in the number of diarrhoeal cases in the city. The cholera outbreak happened at a time when the city was experiencing 
problems with water, sewage reticulation, and similar findings were made in other countries $[10,11]$. A total of 444 cholera cases were seen during the outbreak, and 17 deaths occurred. Due to being prepared, the city managed to prevent local transmission effectively and managed to control the outbreak on time.

An increase in watery diarrhoea was noted in the city between 2009 and 2010. During this period, the number of children less than five years with watery diarrhoea was higher than for those aged 5 years and above. This could be due to the increase in watery diarrhoea in children less than five attributed to rotavirus infection, especially during the winter season. Rotavirus is the most important cause of severe gastro enteritis in infants and young children worldwide. This finding is consistent with Coertese and other studies, who reported that rotavirus causes approximately half a million deaths each year among children less than five years, with more than $80 \%$ of these deaths occurring in developing countries, including Zimbabwe [12, 13, 14, 15].

An increase was noted in the number of males with watery diarrhoea between 2010 and 2012 . Since the prevalence of HIV among men reported by the ZDHS (Zimbabwe Demographic and Health Survey) 2010-2011(21.1 for females against 16.5 for males), is lower than that for females, HIV infection is not responsible for this discrepancy $[9,16]$. The difference in numbers by gender could be related to the hygienic practices of these two groups. It is possible that males were not practicing good hygiene like washing hands before eating or eating unclean food at the workplace during the day. In addition, since females are the ones who usually frequent health facilities in the city, they are more likely than males to receive health education on how to prevent diarrhoea. However, the increase might reflect an increase in the health-seeking behaviour of males after community anti-diarrhoeal campaigns were held in the city.
There was a sharp drop in the number of bloody diarrhoea cases in those aged 5 years and above between 2008 and 2009. This could be attributed to anti-diarrhoeal campaigns which were held in the city every year. The campaigns were done with the aim to reduce diarrhoeal cases in the city through health education on hygiene, water storage, and prevention. These were spearheaded by the environmental health branch [7]. Similar trends were noted in all divisions in the city.

In Northern Suburbs Division, more cases in those aged 5 years and above were seen between 2007 and 2009, compared to children less than 5. This may be attributed to the cholera outbreak, which mainly affected adults during that period. There was no difference in the number of watery and bloody diarrhoea cases for both sexes. In Emakhandeni Division, there were more cases aged 5 years and above with bloody diarrhoea between 2007 and 2009.

This coincides with the cholera epidemic period and might explain the observation. This was followed by an increase in bloody diarrhoea in children under five years. This increase might have been exacerbated by the water situation in the city, as the city was facing water and sewage reticulation challenges $[10,11]$. This might also have to do with the unhygienic environment the children lived in as well as poverty. This is consistent with [4], who reported that there is a strong relationship between poverty, an unhygienic environment, and the number and severity of diarrhoeal episodes, especially in children less than five years. The authors stated that poverty is associated with poor housing, crowding, dirty floors, and lack of access to sufficient clean water or to sanitary disposal of faecal waste.

In Nkulumane Division, the incidence of bloody diarrhoea in females was higher than that in males from 2007 to 2012. This difference could be attributed to the better health-seeking behaviour that is practiced by females in the division. Even when they are sick, males may 
not be attending the clinic for treatment as long as they think the disease is not very severe. This leads to under-reporting of bloody diarrhoea in males.

Northern Suburbs division had the lowest incidence of both watery and bloody diarrhoea. This may be due to the economic status of the division residents. In Northern Suburbs, it is where the eastern suburbs in the city are found. These are low-density suburbs where the majority of affluent people live. The type of housing and general environment is better compared to the high-density suburbs where there might be overcrowding and burst sewers. In addition, people who live in this area might be eating a balanced diet compared to those in highdensity areas, leading to a stronger immunity system. This finding is supported by Keusch Mathan, and others who reported that improvement in economic status, water supply, and environmental sanitation would greatly reduce the significance of diarrhoea as a public health problem $[4,10,11,17]$.

Emakhandeni Division had the highest incidence of bloody diarrhoea throughout the review period. This could be due partly to the presence of housing settlements without water supply in the division. Due to a shortage of clean water, residents might have been drinking contaminated water from open wells and boreholes in the area. In addition, due to the absence of piped water in such settlements, residents were resorting to defecating in the open since water to flush was not available. $[4,18,19$, 20].

There was an increase in the number of stool specimens collected for laboratory investigation between 2008 and 2012, probably due to follow up of clinics to do so. Data on stool specimens collected for 2007 was not available in some clinics. Data on bloody diarrhoea cases by week was not complete for the year 2007. Hence 2007 bloody diarrhoea data by week was not included in the calculation of the thresholds. However, data for the rest of the study years was available and of good quality.

\section{Conclusion}

Overall, there was a decrease in the incidence of both watery and bloody diarrhoea in the city, probably due to anti-diarrhoeal campaigns which are done regularly. Emakhandeni experienced the highest incidence of diarrhoea throughout the review period. More watery than bloody diarrhoea cases occurred in the city. An increase in the number of stool specimens collected for laboratory investigation was recorded. We recommended; Health education in clinics and the community to improve hygienic practices; Advocacy for improved water and sanitation in Emakhandeni, especially in Cowdray Park; Periodic campaigns in Emakhandeni on water safety and proper sanitation; Rotavirus vaccination for underfives; Campaigns to improve health-seeking behaviour in Nkulumane; Updating of thresholds in all clinics for use in monitoring diarrhoea and for clinics to keep all records on diarrhoea.

\section{Availability of Supporting Data}

Supporting data for this article is available.

\section{Conflict of Interest}

The authors declare no conflict of interest.

\section{Author's Contributions}

All the authors contributed in conceiving, designing, and coordination of the study. All the authors helped draft the manuscript. All the authors read and approved the final manuscript.

\section{Acknowledgements}

We would like to thank the Ministry of Health and Child Care (Zimbabwe) for technical and logistical support, the Center for Disease Control (CDC) for technical support, the Bulawayo City Health Department for authority and logistical support to conduct the study. 


\section{References}

[1] World Health Organisation, 2017, Diarrhoeal Disease Factsheet http://www.who.int.

[2] World Health Organisation: 2005, The treatment of diarrhoea, A manual for Physicians and Other Senior Health Workers, $4^{\text {th }}$ Edition; http://www.who.int/publications/2005/9241593180.

[3] United Nations Children's Fund/World Health Organisation: 2009, Diarrhoea, why children are still dying and what can be done. http://www.unicef.org/media/.../Final_Diarrhoea_Re port_October_2009.

[4] Keusch G.T, Fontaine O, Bhargava A, BoschiPinto C, Bhutta Z.A and Gotuzzo E. 2006, Diarrheal Diseases. In: D.T Jamison, J.G Breman, A.R Measham (eds). Disease Control Priorities in Developing Countries $2^{\text {nd }}$ edition; World Bank: 371387. http://www.ncbi.nlm.nih.gov.

[5] World Health Organisation, 2004, Zimbabwe Country Profile of Environmental Burden of Disease.http://www.who.int/entity/quantifying_ehim pacts/national/country/countryprofile/zimbabwe.pdf. [6] World Health Organisation, 2010, Zimbabwe Health

Profile. http://www.who.int/gho/countries/zwe.

[7] Annual Reports City of Bulawayo Health Services Department; 2006-2011.

[8] Banda S: Personal Communication, Health Information Office; City of Bulawayo Health Services Department.

[9] Zimbabwe National Statistics Agency: 20102011, Zimbabwe Demographic and Health Survey. https://dhsprogram.com/pubs/pdf/FR254/FR254.pdf. [10] Prüss-Ustün A, Wolf J, Bartram J, Clasen T, Cumming O, Freeman MC, Gordon B, Hunter PR, Medlicott K, Johnston R, 2019, Burden of disease from inadequate water, sanitation and hygiene for selected adverse health outcomes: An updated analysis with a focus on low- and middle-income countries. Int J Hyg Environ Health. 222(5):765-777. https://pubmed.ncbi.nlm.nih.gov/31088724/.

[11]Null C, Stewart CP, Pickering AJ, Dentz HN, Arnold BF, Arnold CD, Benjamin-Chung J, Clasen T, Dewey KG, Fernald LCH, Hubbard AE, Kariger P, Lin A, Luby SP, Mertens A, Njenga SM, Nyambane G, Ram PK, Colford JM Jr, 2018, Effects of water quality, sanitation, handwashing, and nutritional interventions on diarrhoea and child growth in rural Kenya, a cluster-randomised controlled trial. Lancet Glob Health. Mar;6(3): e316-e329. https://pubmed.ncbi.nlm.nih.gov/29396219/.

[12] Cortese M.M: 2009, Prevention of Rotavirus Gastroenteritis among Infants and Children: Recommendations of the Advisory Committee on Immunisation Practices (ACIP), 58(RR-2): 1-25 http://www.cdc.gov/mmwr.

[13] Hoque SS, Faruque AS, Mahalanabis D, Hasnat A, 1994, Infectious agents causing acute watery diarrhoea in infants and young children in Bangladesh and their public health implications. J Trop Pediatr. 40(6):351-4. https://pubmed.ncbi.nlm.nih.gov/7853440/.

[14] Niyogi SK, Saha MR, De SP, 1994, Enteropathogens associated with acute diarrhoeal diseases. Indian J Public Health 38(2):29-32. https://pubmed.ncbi.nlm.nih.gov/7835992/.

[15]Lloyd S.J, Kovats S.R and Armstrong B.G: 2007, Global diarrhoea morbidity, weather and climate; Climate Research Journal, (34): 119-127 https://www.int-res.com/abstracts/cr/v34/n2/p119$127 /$.

[16] Mahmud I, Das S, Khan SH, Faruque ASG, Ahmed T, 2020, Gender disparity in care-seeking behaviours and treatment outcomes for dehydrating diarrhoea among under-5 children admitted to a diarrhoeal disease hospital in Bangladesh: an analysis of hospital-based surveillance data. BMJ Open. $3 ; 10(9)$.

https://pubmed.ncbi.nlm.nih.gov/32883737/.

[17] Mathan I.V, 1998, Diarrhoeal Diseases: British Medical Bulletin, 54(2): 407-419 http://www.bmb.oxfordjournals.org.

[18] Arvelo W, Blum LS, Nahar N, von Seidlein L, Nahar L, Pack RP, Brooks AW, Pach A, Breiman RF, Luby SP, Ram PK, 2011, Community perceptions of bloody diarrhoea in an urban slum in South Asia: implications for introduction of a Shigella vaccine. Epidemiol Infect, 139(4):599-605 https://pubmed.ncbi.nlm.nih.gov/20546637/.

[19] Melo MC, Taddei JA, Diniz-Santos DR, Vieira

C, Carneiro NB, Melo RF, Silva LR, 2008, Incidence of diarrhea in children living in urban slums in 
Salvador, Brazil. Braz J Infect Dis, 12(1):89-93, https://pubmed.ncbi.nlm.nih.gov/18553022/.

[20] Otsuka Y, Agestika L, Widyarani, Sintawardani N, Yamauchi T, 2019, Risk Factors for
Undernutrition and Diarrhea Prevalence in an Urban Slum in Indonesia: Focus on Water, Sanitation, and Hygiene. Am J Trop Med Hyg, 100(3):727-732. https://pubmed.ncbi.nlm.nih.gov/30693865/. 